\title{
Compreendendo a formação ecológica de monitores ambientais: o caso do Projeto 'Monitores Ambientais de Recursos Hídricos'
}

\author{
Priscila Gonçalves de Souza Salvati ${ }^{1}$ \\ Angélica Cosenza ${ }^{2}$
}

Resumo: O presente trabalho teve como objetivo a compreensão da formação de monitores ambientais, buscando entender conceitos, valores $\mathrm{e}$ comportamentos ambientais construídos pelos jovens monitores participantes do Projeto 'Monitores Ambientais de Recursos Hídricos', conduzido pela Embrapa durante os anos de 2009 e 2010. Buscou-se com esse estudo entender percepções e ações dos monitores em relação ao meio ambiente local, avaliar suas impressões sobre suas atuações na realização das análises de água e analisar se estes se tornaram referência como multiplicadores de conhecimentos nas comunidades em que vivem. Essa pesquisa foi focada nos princípios de pesquisa qualitativa, utilizandose entrevistas semiestruturadas e observação participante. Os monitores mostraram ter apreendido conceitos, valores e comportamentos ambientais. Porém, sua formação parece não ter sido atrelada às questões socioambientais e ao envolvimento comunitário.

Palavras-chave: Monitores ambientais. Recursos hídricos. Educação ambiental.

Abstract: This study aimed to understand the formation of environmental monitors, trying to understand concepts, values and behaviors environmental monitors built by young participants in the project 'Environmental Monitors Water Resources', conducted by Embrapa during the years 2009 and 2010. We tried to understand with this study perceptions and actions of the monitors in relation to the local environment, assess their impressions of their performance in analyzes of water and examine whether they become a reference as multipliers of knowledge in the communities where they live. This research was focused on the principles of qualitative research, using semi-structured interviews and participant observation. The monitors were shown to have grasped the concepts, values and environmental behavior. However, its formation

\footnotetext{
${ }^{1}$ Pós-graduanda em Análise Ambiental na Universidade Federal de Juiz de Fora(UFJF), Juiz de Fora, Brasil, prisalvati@yahoo.com.br

2 Professora assistente da Faculdade de Educação da Universidade Federal de Juiz de Fora(UFJF), Juiz de Fora, Brasil, cosenzaar@ig.com.br
} 
seems to not to have been tied to socio-environmental issues and community involvement.

Keywords: Environmental monitors. Hydric resources. Environmental education.

\section{Comprendiendo la formación ecológica de monitores ambientales: el caso del Proyecto 'Monitores Ambientales de Recursos Hídricos'}

Resumen: El presente trabajo tuvo como objetivo la comprensión de la formación de monitores ambientales, procurando entender conceptos, valores y comportamientos ambientales construídos por los jóvenes monitores participantes del Proyecto 'Monitores Ambientales de Recursos Hídricos', conducido por la Embrapa durante los años de 2009 y 2010. Con este estudio se procuró entender percepciones y acciones de los monitores con relación al medio ambiente local, evaluar sus impresiones sobre sus actuaciones en la realización de los análisis de agua y analizar si estos se volvieron referencia como multiplicadores de conocimientos en las comunidades en que viven. Esta investigación se focó en los principios de investigación cualitativa, utilizando entrevistas semiestructuradas y observación participante. Los monitores mostraron haber aprehendido conceptos, valores y comportamientos ambientales. Aunque, su formación parece no haber sido vinculada a las cuestiones socioambientales y al envolvimiento comunitario.

Palabras clave: Monitores ambientales. Recursos hídricos. Educación ambiental.

\section{1-Introdução}

O presente trabalho foi idealizado a partir do envolvimento de uma das pesquisadoras no projeto liderado pela Empresa Brasileira de Pesquisa Agropecuária (Embrapa) em parceria com a Empresa de Assistência Técnica e Extensão Rural de Minas Gerais (Emater-MG), Instituto Estadual de Florestas (IEF) e escolas estaduais e municipais nos anos de 2009 e 2010. Tal projeto denominou-se "Sistema de monitoramento da qualidade de águas naturais, a exploração agropecuária e a preservação dos recursos hídricos: participação comunitária de produtores de leite de base familiar e quilombolas" e envolveu a formação de jovens de municípios da Zona da Mata e do sul de Minas no monitoramento das águas de rios que banham as comunidades rurais onde vivem. Os jovens participantes eram estudantes e filhos de agricultores familiares que tinham no leite sua principal fonte de renda. Os principais objetivos desse projeto foram: monitorar a qualidade de água de cursos lóticos de água em propriedades de produtores de leite de base familiar e quilombolas, relacionando esta qualidade a sazonalidade e tipo de exploração do solo, e capacitar agentes de 
monitoramento da qualidade de água, tornando-os engajados e referência para a comunidade.

O monitoramento de qualidade de água foi realizado por jovens (com idade entre 16 e 21 anos), que residiam no entorno do Parque do Papagaio (Serra da Mantiqueira) e do Ibitipoca (Lima Duarte). No âmbito desse projeto liderado pela EMBRAPA, os jovens participantes foram escolhidos por meio da ação da escola e da Emater local dos municípios escolhidos, sendo que todos eles foram treinados como agentes de monitoramento ambiental da qualidade de água.

Após a realização do treinamento, os jovens começaram a analisar, em suas comunidades, cursos lóticos de água (córregos e rios). Os parâmetros de $\mathrm{pH}$, turbidez, oxigênio dissolvido, fosfato, amônia, ferro, cloreto, dureza, temperatura, coliforme fecal, coliforme total e Salmonella foram medidos por meio da utilização de "kits" para análise.

$\mathrm{Na}$ ocasião, os monitores enviaram os resultados da análise de água através dos técnicos da Emater local a cada 15 dias, de junho de 2009 até julho de 2010 e, assim foi obtida uma média e a classificação do corpo d'água, conforme a resolução do Conselho Nacional do Meio Ambiente, CONAMA 357 (BRASIL, 2005) $)^{1}$.

As médias das análises no tempo de seca e no tempo chuvoso indicaram a classificação dos corpos d'água em classe 2 e 3. Com base nessa classificação, pode-se dizer que os valores dos parâmetros encontrados indicaram que todos os rios e córregos das comunidades apresentavam poluição difusa. Pôde-se concluir,

${ }^{1}$ De acordo com essa resolução, os corpos de água doce podem ser categorizados em diferentes classes de acordo com parâmetros físicos, químicos e biológicos. As classes são divididas em: classe especial; classe 1; classe 2; classe 3 e classe 4. Destinação das águas de acordo com as classes: classe especial: a) ao abastecimento para consumo humano, com desinfecção; b) a preservação do equilíbrio natural das comunidades aquáticas; e, c) a preservação dos ambientes aquáticos em unidades de conservação de proteção integral; classe 1: águas que podem ser destinadas: a) ao abastecimento para consumo humano, apos tratamento simplificado; b) a proteção das comunidades aquáticas; c) a recreação de contato primário. d) a irrigação de hortaliças que são consumidas cruas e de frutas que se desenvolvam rentes ao solo e que sejam ingeridas cruas sem remoção de película; e) a proteção das comunidades aquáticas em Terras Indígenas; classe 2: águas que podem ser destinadas: a) ao abastecimento para consumo humano, apos tratamento convencional; b) a proteção das comunidades aquáticas; c) a recreação de contato primário. d) a irrigação de hortaliças, plantas frutíferas e de parques, jardins, campos de esporte e lazer, com os quais o publico possa vir a ter contato direto; e) a aqüicultura e a atividade de pesca; classe 3: águas que podem ser destinadas: a) ao abastecimento para consumo humano, apos tratamento convencional ou avançado; b) a irrigação de culturas arbóreas, cerealíferas e forrageiras; c) a pesca amadora; d) a recreação de contato secundário; e) a dessedentação de animais; classe 4: águas que podem ser destinadas: a) a navegação; e b) a harmonia paisagística. (BRASIL, 2005) 
portanto que todas as comunidades em que viviam os jovens monitores ambientais, encontravam-se impactadas pela produção leiteira e fezes humanas (OTENIO et al, 2010).

Ao fim do projeto, constatou-se, no entanto, que nenhum instrumento avaliativo foi utilizado para dar indícios sobre a apreensão de conceitos e temáticas pelos jovens, tais como, preservação e conservação de recursos naturais, qualidade e causas da poluição da água, a formação de novos valores e comportamentos ou a participação comunitária na resolução de problemas. E isso motivou algumas inquietações que se desdobraram em questões para a presente investigação: $\mathrm{O}$ que esses jovens aprenderam? Que sentidos atribuíram ao meio ambiente e aos problemas ambientais que afetam suas comunidades? $\mathrm{O}$ projeto lhes proporcionou novos conhecimentos, habilidades, atitudes, valores, frente aos problemas de suas comunidades? Como esses jovens realizaram a circulação de informações adquiridas no projeto em meio a suas comunidades? Essas questões levantadas ao fim do projeto, levaram-nos a uma reflexão sobre o papel da educação ambiental (EA) na formação de cidadãos ambientalmente conscientes e atuantes. Dessa forma, este trabalho surgiu com o intuito de ser um instrumento avaliativo do impacto do Projeto 'Monitores Ambientais de Recursos Hídricos' e suas atividades na formação destes jovens.

Assim, o presente trabalho objetivou compreender, através dos princípios da pesquisa qualitativa, os saberes, valores e comportamentos ambientais construídos pelos jovens monitores em suas atividades cotidianas e nas comunidades em que vivem. Mais especificamente, buscou-se por meio das significações dos monitores: 1) compreender a influência do projeto em sua formação ecológica; 2) entender mudanças em seus conhecimentos e práticas a partir de seu envolvimento no projeto, e 3) entender seu papel comunitário como multiplicadores da conscientização ambiental.

A crescente notoriedade e legitimidade dos movimentos ecologistas nas últimas décadas vêm fazendo com que haja conscientização a respeito dos problemas ambientais, que acabam conquistando seguidores de valores e comportamentos que implicam em um jeito ecológico de ser, com modos próprios de pensar em si próprio e no impacto de suas atitudes em relação aos outros e ao mundo. Esse modo de ser e viver orientado pelos princípios do ideário ecológico é o que Carvalho (2008) chama de "sujeito ecológico".

Para a autora, o conceito de sujeito ecológico é situado dentro da perspectiva de meio ambiente como sendo um campo de relações sociais que toma parte entre as tentativas de ressignificar as negociações da experiência individual e coletiva. Seguindo esse pensamento, a perspectiva é a de que o sujeito ecológico, sob o aspecto da gestão social, seja capaz de dividir com os outros uma compreensão política e técnica da crise socioambiental, sendo responsável por usar procedimentos legais para enfrentá-la, através da mediação de conflitos e planejamento de ações ambientalmente corretas (CARVALHO, 
2008).

Conforme a descrição de Carvalho é coerente dizer que o sujeito ecológico deve atuar como agente de transformação e multiplicação, agindo de forma ativa e interessada diante de problemas e conflitos ambientais locais. Esse estudo parte de um referencial teórico que articula os ideais de um sujeito ecológico no âmbito da defesa de uma educação ambiental crítica, a qual busca politizar o debate socioambiental, articular as diversas dimensões da sustentabilidade e problematizar as contradições dos modelos de desenvolvimento e de sociedade experimentadas local e globalmente (LAYRARGUES e LIMA, 2011). Assim, procura-se nesse projeto compreender os saberes ecológicos que constituem os sujeitos de pesquisa, e os conhecimentos lhes serviram ao exercício da inserção e participação locais.

\section{2- Metodologia de estudo}

A investigação qualitativa é uma abordagem de pesquisa bastante privilegiada nas ciências humanas e em estudos na área de educação ambiental, podendo ser construída através de várias metodologias, e estratégias variadas de coletas de dados, tais como vídeos, questionários, fóruns de discussão, entrevistas gravadas ou escritas.

De acordo com Bogdan e Biklen (1994) a investigação qualitativa apresenta cinco características principais: 1) a fonte direta dos dados é o ambiente natural. Os pesquisadores qualitativos frequentam seus locais de estudo porque se preocupam com o contexto; 2) é descritiva, sendo os dados recolhidos em forma de palavras ou imagens; 3) os investigadores qualitativos interessam-se mais pelo processo do que simplesmente pelos resultados e, 4) tendem a analisar seus dados de forma indutiva; 5) o significado é de importância vital na abordagem qualitativa, estando os investigadores interessados no modo como diferentes pessoas dão sentido às suas vidas.

A pesquisa qualitativa é uma atividade que localiza o pesquisadorobservador no mundo. Essa abordagem transforma o mundo em representações, incluindo as notas de campo, as entrevistas e as conversas, postas a entender os significados que os sujeitos conferem ao que foi exposto por eles (DENZIN \& LINCOLN, 2006). Assim, a abordagem qualitativa reconhece a relevância do sujeito, dos valores, dos significados e intenções da pesquisa, corroborando a importância do contexto do qual os dados são construídos e da inclusão da voz dos atores sociais (CHIZZO'T'TI, 2006).

Partindo dessa abordagem, esse estudo privilegiou duas estratégias de pesquisa: a observação participante, que permitiu uma melhor compreensão dos sujeitos em seus contextos de vida e a entrevista narrativa semi-estruturada, que buscou o entendimento dos jovens sobre meio ambiente e o impacto do projeto em suas vidas. 
Os dados foram coletados entre os meses de março e maio de 2010, e foram obtidos em visitas à residência de 14 dos 17 jovens do projeto Monitores Ambientais, que residem em oito municípios (Lima Duarte, Bocaina de Minas, Santa Rita do Ibitipoca, Carvalhos, Bias Fortes, Pedro Teixeira, Santana do Garambéu e Alagoa), sendo cinco em torno do Parque Estadual de Ibitipoca e os outros três estão no Núcleo Mantiqueira II do Corredor Ecológico da Mantiqueira.

As observações foram sistematizadas em notas de campo feitas após cada visita e posteriormente num esforço reflexivo, transformadas em notas expandidas. Essas notas ao serem confrontadas com as entrevistas, permitiram a construção do corpus empírico da pesquisa (DENZIN \& LINCOLN, 2006). As entrevistas foram gravadas digitalmente e foram realizadas individualmente mediante autorização dos pais e dos jovens, sendo que estes últimos leram e assinaram o Termo de Consentimento Livre e Esclarecido. Depois de gravadas, foram transcritas e organizadas de acordo com as questões de pesquisa.

As questões da entrevista foram construídas após o estabelecimento de familiaridade com o campo e com os sujeitos de estudo conforme sugerem Jovchelovitch \& Bauer (2007), e embasadas nos objetivos e interesses dessa pesquisa. Segue abaixo as temáticas norteadoras das entrevistas:

1) Significados atribuídos ao meio ambiente;

2) Valores e comportamentos desenvolvidos ao longo da experiência como monitor (a) ambiental;

3) Importância desses valores e comportamentos na comunidade em que o monitor (a) vive;

4) Participação e engajamento comunitários do monitor (a).

\section{3- Os monitores ambientais e suas formações ecológicas}

Nesta seção, será caracterizado o processo de monitoramento de água realizado pelos monitores durante o decorrer do projeto e o contexto de vida resumido dos jovens participantes desse estudo.

Os locais visitados no projeto da Embrapa e que foram tomados também como contextos de pesquisa para este estudo particular foram: Lima Duarte, Santa Rita do Ibitipoca, Bias Fortes, Pedro Teixeira, Santana do Garambéu, Carvalhos, Bocaina de Minas e Alagoa, sendo que os municípios que detêm em seu território o Parque Estadual do Ibitipoca, também fazem parte do Corredor Ecológico da Mantiqueira juntamente com os outros do Núcleo Mantiqueira II.

A Mantiqueira é caracterizada pela presença de diversos atores que interagem entre si e com a natureza: agricultores familiares, turistas, empresários e órgãos públicos municipais, estaduais e federais. A pecuária leiteira é o sistema produtivo predominante, porém com baixo rendimento econômico. Pastos pobres, poucas áreas planas para pastagens, justificam a baixa produtividade verificada na área do Corredor (GOMES, 2005). 
Em todas as localidades visitadas, a agricultura familiar é uma atividade de grande relevância econômica. Segundo Silva (2009) a agricultura familiar é percebida como um modo de vida sustentável, que inclui tanto a dimensão econômica, social e ambiental, no qual esses atores constroem valores, códigos, rituais e significados culturais com a finalidade de dar sentido à própria existência e ao entorno.

A localização estratégica do Corredor Ecológico da Mantiqueira, inserido geograficamente entre os estados do Rio de Janeiro, São Paulo e Minas Gerais, traz consigo uma forte pressão sobre a economia e ocupação da região. Segundo Guivant (1997), as principais pressões sobre o meio ambiente no Corredor em estudo estão vinculadas às formas tradicionais de uso da terra, exemplificadas pela pecuária extensiva, queimadas e plantio em áreas protegidas ou com grande declividade. Isso motivou a equipe do projeto da EMBRAPA investigar como estavam estabelecidas as atividades de pecuária leiteira e de agricultura, que se mal manejadas, podem prejudicar a qualidade da água.

As interpretações das entrevistas com seu entrecruzamento com os dados da observação levaram-nos a três temáticas interpretativas sobre os monitores ambientais e seus processos de formação ecológica: representação de meio ambiente; saberes, valores e comportamentos ecológicos construídos e o envolvimento da comunidade no projeto.

Por meio desses temas procurou-se compreender a formação ecológica e a aplicação prática nas atitudes cotidianas de cada jovem dos conceitos, valores e comportamentos ambientais apreendidos durante a participação nas atividades do Projeto Monitores.

\subsection{Os significados atribuídos a meio ambiente}

Apesar de haver um consenso sobre a emergência e a seriedade da crise ambiental contemporânea, há diferentes representações político-ideológicas, por detrás de discursos por vezes conflitantes, que moldam a forma como indivíduos e grupos sociais passam a compreender meio ambiente e os problemas socioambientais. A produção destes discursos no campo ambiental se faz visível quando analisamos diferentes concepções sobre o que seja meio ambiente, assim como respostas, posicionamentos ou possíveis explicações de diferentes setores sociais às indagações sobre causas, conseqüências e alternativas à crise socioambiental contemporânea.

A identificação de diferentes sentidos conferidos a "meio ambiente", deve, para Reigota (2004) ser um passo importante na educação ambiental, para colocar em evidência os saberes daqueles que participam do processo educativo.

Com base nas palavras dos monitores, foi possível identificar três principais significações sobre meio ambiente. A primeira delas - naturalista - esteve presente associando o tema meio ambiente com os aspectos naturais e abióticos 
(REIGOTA, 1995), como se pode notar nas palavras a seguir: "O meio ambiente que a gente mora, a água, a fauna, a flora, tudo que far parte do meio ambiente" (Gustavo)2. O discurso de Diogo também expressa essa idéia: "A natureza, a mata, floresta, tudo em geral que fala de natureza".

Essa primeira significação tem seu discurso bastante identificado com práticas conservacionistas, na defesa de uma natureza intocada ou na preservação da biodiversidade. Layrargues e Lima (2011) identificam também esse modo de conceber o meio ambiente, típico de alguns setores do movimento ambientalista, em discursos e práticas pedagógicas, quando relações sociedade-natureza são enfatizadas sem, contudo, aprofundar as causas da problemática ambiental e as relações com determinados modelos de desenvolvimento e de interações entre ciência e tecnologia (C\&T). O discurso conservacionista na educação, segundo os autores assume o ambiente por seus aspectos naturais, enunciando os problemas ambientais como frutos de desconhecimento de princípios ecológicos e maus comportamentos.

A segunda significação observada em uma única resposta demonstrou uma perspectiva de relação/interação, inclusão/globalidade e de dependência na relação entre ser humano-natureza (CARNEIRO, 1999), como pode ser percebida abaixo: "Tudo que nos envolve, nos sustenta e nos faz sobreviver. A base de tudo pra sociedade hoje em dia" (Daniel). Essa visão, diferentemente da primeira, inclui o humano em suas considerações, apesar de localizá-lo implicitamente no texto. Essa tendência afina-se com ideários contemporâneos do movimento ambientalista e da educação ambiental que buscam articular as questões ambientais às sociais (LAYRARGUES \& LIMA, 2011).

Outra significação associou o termo de maneira mais pragmática, relacionando a utilidade dos recursos naturais para a sobrevivência do homem, a conservação/cuidado que se deve ter em relação ao meio ambiente para usufruto humano. Como exemplo dessa visão cita-se as palavras de Ana: "Meio ambiente é conservar a natureza, não sujar, preservar, né? Porque igual, a água pode acabar se a gente não preservar". Semelhante fala parece-nos indicar que a resolução dos complexos problemas ambientais passa pela soma dos esforços individuais de conservação e cuidado. Essa maneira pragmática de olhar o meio ambiente surge no âmbito do movimento ambientalista, bastante associada a uma percepção despolitizada das relações socioambientais, que aposta em ações factíveis para resultados orientados a um futuro sustentável, embora dentro de um limite que não ultrapasse as fronteiras do economicamente viável e da conservação do status quo.

Em contexto de problemas ambientais e de processos formativos, entende-se que os sujeitos são também interpelados por significações ambientais advindas de outras práticas sociais (provenientes da mídia, da escola, da família, etc) e são igualmente construtores de novas significações. Assim, constatou-se que quase a metade dos monitores definiu meio ambiente sob o ponto de vista naturalista, reduzindo-o à sua 
dimensão biótica e abiótica, talvez influenciados pela formação recebida pelo projeto Monitores Ambientais de Recursos Hídricos', bastante identificado com um ideário conservacionista. Entretanto, para a formação de sujeitos críticos, capazes de pensar e agir na esfera ambiental é necessário que se ampliem concepções sobre o meio ambiente, bem como a problemática ambiental, dentro de uma visão contextualizada da realidade socioambiental (BEZERRA \& GONÇALVES, 2007).

\section{2- Saberes, valores e comportamentos ecológicos construídos}

A Educação Ambiental é uma práxis educativa e social que tem por finalidade a construção de valores, conceitos, habilidades e atitudes que possibilitem o entendimento da realidade de vida e atuação consciente e responsável dos atores sociais individuais e coletivos no ambiente (LOUREIRO, 2002).

Tendo em vista a relevância da construção de novos valores e comportamentos ambientais como pilares fundamentais para a consolidação da educação ambiental, indagou-se aos sujeitos sobre o que havia mudado após a participação nesse projeto. Os jovens, em sua maioria, referenciaram uma maior conscientização na conservação do meio ambiente, apesar desse ter sido em grande parte das significações, expresso como sinônimo de natureza. De acordo com Ruscheinsky (2001), a consciência ambiental torna-se possível se o sujeito participar diretamente na construção de seu conhecimento. Essa consciência pode ser evidenciada no seguinte depoimento: "A gente passa a perceber mais como é importante a saúde da água, não poluindo" (Rita).

${ }^{2}$ Utilizou-se nomes fictícios para resguardar a privacidade dos monitores.

Os monitores explicitaram o conhecimento técnico que adquiriram após a participação no projeto falando: "[...] através da água que a gente faz. análise você pode descobrir várias coisas, se tá poluido ou não" (André). Constatou-se através das análises de água e das observações em campo que os principais agentes poluidores dessas comunidades são o efluente derivado da produção leiteira, que é despejado diretamente nos cursos d'água e as fezes do gado devido ao acesso facilitado a estes. Sendo assim, a comunidade deveria buscar o cercamento dos corpos d'água e a instalação de uma estação de tratamento de efluentes dos pequenos laticínios em cada município, estruturando cooperativas locais para melhorar a qualidade da água consumida.

Dessa forma, a educação ambiental surge como uma importante ferramenta para preparar os indivíduos para que possam, a partir de atividades práticas e conhecimentos adquiridos, agirem de forma pró-ativa na defesa de sua qualidade de vida. 
Procurou-se entender os valores e comportamentos desenvolvidos ao longo da experiência como monitor ambiental e sob esse aspecto, a maior parte das significações dos jovens abordou os temas de preservação da natureza, indistintamente de conservação da natureza. As palavras do monitor João remetem à importância conferida à preservação e mudança de comportamentos em relação ao meio ambiente após a participação no projeto, como se observa abaixo:

"Isso mudon o interesse que eu tinha pela água, natureza e meio ambiente. Que antes en não me importava muito com negócio de água, preservar e que se a água é limpa ou suja. Agora eu importo mais. Passei a preservar mais as nascentes de água, que antes eu não cuidava, lixo que en jogava no rio e não jogo mais" (João).

É interessante notar novamente como as noções sobre conservação e preservação se confundem na voz dos monitores. Isso indica-nos uma fragilidade conceitual no processo formativo empreendido junto aos monitores, uma vez que "preservar" pressupõe deixar o ambiente natural sem interferência humana, enquanto que "conservar" possibilita sua utilização de forma racional e abre possibilidades criativas na relação sociedade/natureza.

Além disso, alguns monitores basearam seus discursos na conscientização e percepção ambiental, dizendo: "Tipo assim, en pensava que um papelz̧inho de bala que a gente pegava e jogava fora, ah não tem importância, pode jogar no chão. Mas aquilo, aquele papelzinho pode fazer a diferença e muito. Ai com isso me conscientizou muito" (Paula). As atitudes individuais são importantes para inibir a poluição dos corpos hídricos, porém é imprescindível a atuação do poder público como regulador do uso da água, que é um bem comum de todos.

Os monitores ambientais demonstraram por suas falas terem adquirido uma consciência ambiental durante o projeto, transformando suas percepções, comportamentos e estabelecendo uma relação de cuidado com o meio ambiente. Apesar disso, os jovens não mencionaram terem aplicado esse aprendizado em posicionamentos ou atitudes críticas frente aos seus problemas socioambientais locais.

Para Loureiro (2004b), a EA crítica propõe a redefinição do modo como os seres humanos se relacionam entre si e com o planeta, em que o indivíduo consciente da problemática ambiental seja capaz de interferir na realidade e transformá-la. Nesse sentido o objetivo de uma EA crítica/transformadora poderia ser pensado nessa realidade, como o de contribuir para a mudança de valores e atitudes, formando um sujeito ecológico capaz de identificar e problematizar as questões socioambientais e agir sobre elas (CARVALHO, 2008).

\section{3- $\mathrm{O}$ envolvimento dos monitores ambientais em suas comunidades}

De acordo com Loureiro (2004c), o educar vincula as esferas individuais às práticas coletivas, cotidianas e comunitárias, que por sua vez, fornece aos sujeitos 
o significado de fazer parte da sociedade, exercendo ativamente a cidadania. Baseado nesse sentimento de pertencer e agir na esfera social, o autor define o conceito de participação, dizendo:

Participar é compartilhar poder, respeitar o outro, assegurar igualdade na decisão, propiciar acesso justo aos bens socialmente produzidos, de modo a garantir a todos a possibilidade de fazer a sua história no planeta [...]. Participação significa o exercício da autonomia com responsabilidade, com a convicção de que a nossa individualidade se completa na relação com o outro no mundo, em que a liberdade individual passa pela liberdade coletiva. (LOUREIRO, 2004c p.18).

Tomando como referência esse conceito, entende-se que projetos de educação ambiental, vinculados a uma perspectiva crítica, emancipatória de educação, contribuem para estimular os sujeitos a atuar mais nos problemas ambientais locais, incentivando-os a tomadas de decisão em questões que envolvam sua qualidade de vida.

Observou-se que grande parte dos jovens parece compreender que os valores de conservação/cuidado e de conscientização/percepção ambiental que adquiriram na participação do Projeto Monitores Ambientais, foram importantes para fazer com que eles passassem a alertar a população para adotar atitudes ambientalmente corretas. Semelhante significação pode ser vista nas palavras de Ana: "Porque eles estão vendo que eu tô fazendo isso e eles me perguntam e eu falo pra eles que não é pra sujar a água, que pode infectar e pode trazer risco pra gente mesmo em casa".

Os monitores que mostraram bastante preocupação pela preservação ou conservação do meio ambiente destacaram seu interesse em garantir primeiramente uma água de qualidade pra seu consumo e, consequentemente, para a produção leiteira, que representa seu principal meio de sobrevivência.

Alguns monitores responderam que não houve interesse de suas respectivas comunidades por esses valores apreendidos durante o projeto. A monitora Sara ressalta em sua fala, que o desinteresse em sua comunidade ocorre principalmente por ser uma região turística, dizendo: "Aqui é muito complicado porque, até mesmo assim é uma cidade turística, as pessoas vêm e falam que não tem latão de lixo pra jogar o lixo e geralmente eles jogam na rua, porque não têm esses latões. E isso assim, complica muito. Suja muito as ruas".

Daniel aborda o desinteresse pela conservação do meio ambiente destacando a falta de preocupação das pessoas com as mudanças climáticas, que podem afetar não só o ambiente, mas a qualidade de vida destas, falando: “Aqui esses tipos de valores são meio largados. A comunidade em si não tem essa preocupação com o meio ambiente, eles pensam que o meio ambiente em si, a temperatura, as mudanças climáticas, vão ser iguais pra sempre, nunca vão mudar".

Percebeu-se com essas falas que algumas comunidades não estão 
preocupadas com as questões de conservação/preservação ambiental e/ou não foram sensibilizadas para isso, mesmo após as atividades de análise de água, realizadas pelos monitores nos corpos hídricos dessas comunidades.

As falas dos monitores refletem os valores e comportamentos que parecem ter sido adquiridos através da participação no projeto e por suas experiências de vida, conforme a fala do monitor Diogo que disse: “[...] é bom pra água, pra natureza, pra tudo".

O meio ambiente é um lugar de cooperação e de parceria para realizar as mudanças desejadas por uma coletividade, sendo importante viver e agir em conjunto, em "comunidades de aprendizagem e de prática". Assim, para uma intervenção eficaz no meio é preciso que se aprenda a discutir, a argumentar e a comunicar-se por meio de um diálogo entre os saberes científicos, de experiência e tradicionais (SAUVÉ, 2005).

Dessa forma, na última questão da entrevista visou-se compreender como os jovens tentaram envolver a comunidade com questões ambientais. A monitora Mariana disse que: "[...] passando pra frente, como é a importância da água na nossa vida, pra gente ajudar na preservação. Porque um só não vai adiantar, tem que ter a colaboração de todo mundo pra preservação do meio ambiente". A jovem comentou durante a entrevista ter o hábito de falar informalmente com as pessoas de sua comunidade da importância das análises de água que ela realiza, com a finalidade de fazer com que as pessoas também possam cuidar mais da água para diminuir a poluição.

A monitora Laura, do município de Carvalhos considerou que: "Falar sobre a importância do meio ambiente e tentando conscientizar as pessoas que não pode fazer essas coisas que prejudicam o meio ambiente". No término da conversa com a entrevistadora, Laura disse ter comentado na sala de aula com os colegas sobre a sua atuação no Projeto Monitores Ambientais, e, ainda, que estes ficaram curiosos em saber como estava a qualidade da água amostrada, da dificuldade da realização das análises e sobre a utilidade destas.

Através das falas dos sujeitos expostas acima, conclui-se que os jovens somente falaram do projeto e dos temas nele envolvidos de maneira informal para as comunidades, sem uma intervenção efetiva e organizada dentro destas. Isso mostrou certa fragilidade por parte do projeto em estimular a participação dos jovens para contribuir no processo de construção de novos valores e comportamentos comunitários, assim como da cobrança de decisões políticas das instituições responsáveis por minimizar ou resolver estes problemas (ALEIXANDER, 1995 apud FERREIRA \& TOMAZELLO, 2001).

As falas dos monitores carregam marcas de um modelo de educação ambiental de visão ingênua, que aposta na adoção de comportamentos corretos para conservação de recursos naturais. Os discursos dos jovens parecem sugerir um modelo tradicional de educação ambiental, possuindo um enfoque pragmático e instrumental (LOUREIRO, 2004a), voltado para a solução de 
problemas locais, a partir de atividades pontuais e específicas (RODRIGUES, 2008).

De acordo com os autores estudados essa abordagem de educação não é capaz de atuar na formação de sujeitos críticos e participativos de forma a contribuir para a construção de sociedades ambiental e socialmente mais justas e equilibradas (TOZONI-REIS, 2005).

Dentro da perspectiva da educação crítica, o ser humano não pode ser considerado como algo à parte da natureza, ele deve se sentir inserido no meio ambiente, para que haja com mais cuidado e responsabilidade dentro do seu mundo. Esse projeto educativo assume a educação ambiental como prática que intervêm na construção social de conhecimentos inseridos na vida dos sujeitos. Assim, pode-se dizer que a pretensão da EA crítica é provocar processos de mudanças sociais (CARVALHO, 2008).

Além disso, essa corrente de educação privilegia a perspectiva dos atores sociais, possibilitando a consolidação de uma prática contextualizada e crítica, a qual evidencia as causas do uso irracional dos recursos naturais e sua transformação (LOUREIRO, 2004c).

Considerando o conceito de sujeito ecológico, a contribuição da EA crítica segundo Carvalho (2008), seria a de consolidar uma ética que atrelasse a formação ecológica e os valores emancipadores para a construção de uma cidadania ambientalmente sustentável.

\section{4- Considerações finais}

Os monitores ambientais mostraram ter apreendido conceitos, valores e comportamentos ambientais em direção a um maior respeito e conservação da natureza. Isso parece-nos ter satisfeito os objetivos do projeto 'Monitores Ambientais de Recursos Hídricos' da Embrapa, que originalmente investia na formação de agentes de monitoramento de recursos naturais para sua conservação.. Entretanto, esse aprendizado parece não ter sido atrelado às questões socioambientais e à participação comunitária.

O projeto "Monitores Ambientais de Recursos Hídricos" parece ter se concentrado em ensinar conceitos científicos, promover comportamentos ambientalmente corretos e monitorar a qualidade de água local, apesar das falas terem denunciado por exemplo algumas inconsistências conceituais como a não diferenciação entre "preservar" e "conservar" a natureza. No entanto, não privilegiou o conhecimento socioambiental local e a intervenção crítica, participativa e cidadã dos jovens em relação ao meio ambiente dentro de suas comunidades.

Dessa forma, pode-se considerar que houve uma fragilidade na formação de sujeitos ecológicos durante o projeto, pois, apesar de ter havido mudanças nos valores e comportamentos dos jovens em relação ao meio ambiente, não foi 
estimulada a problematização e a atuação política na dimensão socioambiental local. Pode-se corroborar essa observação com uma descrição do sujeito ecológico por Carvalho (2008, p.106) que considera que o sujeito ecológico "partilhe de uma compreensão política e técnica da crise socioambiental, sendo responsável por adotar procedimentos e instrumentos legais para enfrentá-la, por mediar conflitos e planejar ações".

Dessa forma, sentiu-se falta nas significações dos sujeitos estudados, de uma compreensão complexa e ampla da realidade socioambiental, para além do conservacionismo, em que os monitores pudessem se entender como parte constituinte e transformadora de seus contextos de vida.

\section{Referências Bibliográficas}

BEZERRA, T. M. O. \& GONÇALVES, A. A. C. Concepções de meio ambiente e educação ambiental por professores da Escola Agrotécnica Federal de Vitória de Santo Antão - PE. Biotemas. Florianópolis, 2007, v. 20, p.124.

BOGDAN, R. C.; BIKLEN, S. K. Investigação Qualitativa em Educação. Portugal: Porto Editora, 1994. p.47-51.

BRASIL. Conselho Nacional do Meio Ambiente (CONAMA). Resolução do $N^{\circ} 357$, de 18 de Março de 2005. Dispõe sobre a classificação dos corpos de água e diretrizes ambientais para o enquadramento, bem como estabelece as condições e padrões de lançamento de efluentes e dá outras providências. Diário Oficial da União, Brasília, 2005.

CARNEIRO, S. M. C. A dimensão ambiental da educação escolar de $1^{a}$ a $4^{a}$ séries do ensino fundamental na rede pública da cidade de Paranaguá. 1999. 320f. Tese de Doutorado - Universidade Federal do Paraná, Paraná, 1999.

CARVALHO, I. C. M. Educação ambiental: a formação do sujeito ecológico. São Paulo: Cortez, 2008. 256p.

CHIZZOTTI, A. Pesquisa qualitativa em ciências humanas e sociais. Petrópolis, RJ: Vozes, 2006. p. 53.

COSTA, C.; HERRMANN, G. Plano de ação do Corredor Ecológico da Mantiqueira. Valor Natural. Belo Horizonte, 2006. p.64.

DENZIN, N. K.; LINCOLN, Y. S. O planejamento da pesquisa qualitativa: teorias e abordagens. Porto Alegre: Artmed, 2006. p. 17.

FERREIRA, T. R. C. \& TOMAZELLO, M. G. C. Avaliação de um projeto de Educação Ambiental Via Internet: O programa Educ@r. Revista Pixel-Bit. Sevilha, v. 16, n. 16, p.2, 2001. Disponível em: http://www.sav.us.es/pixelbit/pixelbit/articulos/n16/n16art/art161.htm. Acesso em: 20/01/2012. 
GOMES, M. M. Diagnóstico Sócio-Econômico do Corredor Ecológico da Mantiqueira. Valor Natural, Belo Horizonte. Disponível em: www.valornatural.org.br. Acesso em: 06 de set. 2010.

GUIVANT, J. S. Heterogeneidade de conhecimentos no desenvolvimento rural sustentável. Cadernos de Ciência e Tecnologia. Brasília, 1997, v. 14, n. 3. p. 411-447.

JOVCHELOVITCH, S. \& BAUER, M. W. Entrevista narrativa. In: BAUER, M. W.; GASKELL, G. (eds.). Pesquisa qualitativa com texto, imagem e som: um manual prático. Petrópolis, RJ: Vozes, 2007. p. 97.

LIMA, G. F. da C. Crise Ambiental, educação e cidadania: os desafios da sustentabilidade emancipatória. In: LOUREIRO, C. F. B; LAYRARGUES, P.P.; CASTRO, R.S. de (coords.). Educação Ambiental: repensando o espaço da cidadania.São Paulo: Cortez, 2002. p. $120-129$.

LAYRARGUES, P. P.; LIMA, G. Mapeando as Macro-tendências politico-pedagógicas da Educação Ambiental no Brasil. In: VI Encontro Pesquisa em Educação Ambiental. USP: Ribeirão Preto. Anais... 2011. 1 CD-ROM.

LOUREIRO, C.F.B. Educação ambiental e movimentos sociais na construção da cidadania ecológica e planetária. In: LOUREIRO, C. F. B; LAYRARGUES, P. P.; CASTRO, R. S. de (coords.). Educação Ambiental: repensando o espaço da cidadania. São Paulo: Cortez, 2002. p.69.

. Trajetória e fundamentos da educação ambiental. São Paulo: Cortez, 2004a, p.89-97.

Educação ambiental transformadora. In: LAYRARGUES, P. P. (org.). Identidades da educação ambiental brasileira. Brasília: MMA, 2004b, p.75-84.

Educar, participar e transformar em educação ambiental. Revista Brasileira de Educação Ambiental. Brasília, 2004c, v.1, n.00. p.18.

MOSCOVICI, S. La psychanalise, son, image et son publique. 2. ed. Paris: PUF, 1976. p. 26.

OTENiO, M. H.; CARVAlHo, F. G. ; SAlvATI, P. G. S. ; EVARISTO, F. J. ; HOTT, M. C. Monitoramento da qualidade de águas naturais em propriedade rural leiteira, classificação do corpo hídrico. In: XIV Enasb/ SILUBESA - Simpósio lusobrasileiro de engenharia sanitária e ambiental. Porto. Anais...2010. 1 CD -ROM

REIGOTA, M. Meio ambiente e representação social. São Paulo: Cortez, 1995. p. 48.

. Meio Ambiente e representação social. São Paulo: Cortez, 2004, p.14-68.

RODRIGUES, A. C. A educação ambiental e o fazer interdisciplinar na escola. Araraquara: Junqueira\&Marin, 2008, p. 19-31.

RUSCHEINSKY, A. Meio ambiente e percepção do real: os rumos da educação ambiental nas veias das ciências sociais. Rev. eletrônica Mestrado Educação Ambiental. Rio Grande-RS, p.37. v.07 out./nov./dez, 2001. Disponível em: www.remea.furg.br/mea/remea/vol7/aloisio.pdf. Acesso em: 02 ago. 2010. 
SAUVÉ, L. Educação Ambiental: possibilidades e limitações. Revista de Educação e Pesquisa. São Paulo, 2005, mai/ago, vol.31, n²2. p.318.

SILVA, J. S. Agricultura familiar e inovação paradigmática na pesquisa agropecuária: contexto, interação e ética para a inclusão social. In: SOUZA, I. S. F.; CABRAL, J. R. F (orgs.). Ciência como instrumento de inclusão social. Brasília: Embrapa Informação Tecnológica, 2009, p.343.

SOUZA, L. B. \& SILVA, F. K. A. Meio ambiente e educação ambiental segundo as representações de estudantes do curso de geografia: um estudo na Universidade Federal de Tocantins, Campus de Porto Nacional. In:VII Encontro de Pesquisa em Educação Ambiental- EPEA. Rio Claro. Anais... 2007. 1 CD-ROM.

TOZONI-REIS, M. F. C. A construção coletiva do conhecimento e a pesquisa-ação participativa: compromissos e desafios. Pesquisa em Educação Ambiental. Botucatu, 2007, v. 2, n.2. p. 106.

Artigo recebido em 10/08/2011

Artigo aprovado em 16/09/2011 